\title{
Problems of heating and ventilation in small university lecture hall
}

\author{
Mária Budiaková ${ }^{1, *}$ \\ ${ }^{1}$ Slovak University of Technology in Bratislava, Nám. slobody 19, 81245 Bratislava, Slovakia
}

\begin{abstract}
The paper is oriented on the problems of heating and ventilation in small university lecture hall. Providing the optimal parameters of thermal comfort is immensely important for students of university in small university lecture hall. Incorrectly functioning heating and ventilation can disrupt thermal comfort. Reconstruction took place in small university lecture hall. The original windows were exchanged for modern wood tight windows. Experimental measurements were carried out in winter season in 2016 in this small university lecture hall, in order to evaluate the thermal comfort and $\mathrm{CO}_{2}$ concentration after the reconstruction. The device Testo 480 was used for measurements. Obtained values of air temperature, air relative humidity, air velocity, globe temperature, indexes PMV, PPD and $\mathrm{CO}_{2}$ concentration are presented in the graphs. Heating, ventilation and operation of small university lecture hall were evaluated on the basis of parameters of thermal comfort and $\mathrm{CO}_{2}$ concentration. Principles how to design the heating and ventilation in small university lecture halls are in the conclusion of the paper. Furthermore, there are presented recommendations how to operate the heating and ventilation in existing small university lecture halls.
\end{abstract}

\section{Introduction}

In old university buildings, it is very difficult rather impossible to provide thermal comfort, what also relates to incorrect architectural design, old not tight windows, not insulated peripheral wall, insufficient controlled and regulated heating system and to missing mechanical ventilation system. Therefore, new university buildings should have such thermotechnical parameters, energy economical regulated heating system and mechanical ventilation system that would enable provision of thermal comfort in small university lecture halls with high quality.

Securing of thermal comfort in small university lecture hall is very important because students spend in schoolrooms the majority of their time in school. Thermal comfort in the small university lecture hall is defined as the state of mind that expresses satisfaction with the surrounding environment. The fundamental quantities for the evaluation of the thermal comfort are internal air temperature, operative temperature, globe temperature, air relative humidity and air velocity [1]. Then the thermal comfort is evaluated with index PMV (Predicted mean vote) and index PPD (Predicted percentage dissatisfied) [2-3]. Not

\footnotetext{
*Corresponding author: budiakova@,fa.stuba.sk
} 
fulfilling the parameters of the thermal comfort in the small university lecture hall contributes to the high sickness rate of students especially in the winter [4-5]. Not correctly provided thermal comfort also increases energy intensity of university schoolrooms.

Classroom environment is characterized by a high density of students and so the main problem is usually indoor air quality especially high $\mathrm{CO}_{2}$ concentration, which is generated by human presence (metabolism, respiration). $\mathrm{CO}_{2}$ levels that are unusually high indoor climate may cause students drowsiness, headaches, or decrease of their activity. Humans are the main indoor source of carbon dioxide in the most of the buildings. Indoor $\mathrm{CO}_{2}$ levels are an indicator of the adequacy of outdoor air ventilation relative to indoor student density and metabolic activity. In order to eliminate the most complaints, the total indoor $\mathrm{CO}_{2}$ level should be reduced to a difference of less than $600 \mathrm{ppm}$ above outdoor levels.

In the small university lecture hall, the minimal value of an operative temperature $20^{\circ} \mathrm{C}$ must be fulfilled. Small university lecture halls in Slovakia are heated by convective heating elements, Fig. 1. Big massive sills and decoration overlays of convective heating elements significantly increase energy demands and menace the provision of thermal comfort, therefore their application is undesirable. The right size and position of convective heating elements must ensure that the local thermal discomfort will not arise. Local thermal discomfort (the thermal dissatisfaction) can also be caused by unwanted cooling or heating of one particular part of the body [6]. The most common cause of the local thermal discomfort is the draught but local discomfort can also be caused by an abnormally high vertical temperature difference between head and ankles, by too warm or too cool floor, or by too high radiant temperature asymmetry. People are most sensitive to radiant asymmetry caused by a warm ceiling, a cool wall (windows, glazed facade), a cool ceiling or by a warm wall. The major problem in the small university lecture hall are cool windows; therefore, their surface should be minimized to just to provide the daily lighting.

Thermal comfort in the small university lecture halls in Slovakia is not provided and often arises the local thermal discomfort. Therefore, this research was focused on the evaluation of the thermal comfort parameters and $\mathrm{CO}_{2}$ concentration in small lecture hall.

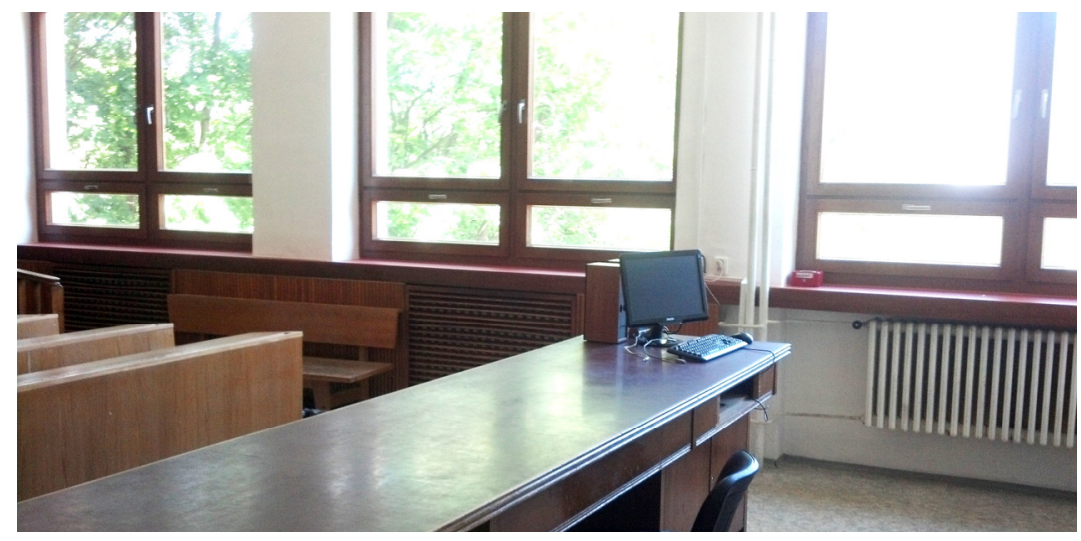

Fig. 1. Small university lecture hall with convective heating elements.

\section{Characteristic of experimental measurements}

Experimental measurements were carried out in the small university lecture hall - Fig. 1 at the Slovak University of Technology in Bratislava, Faculty of Architecture in the beginning of March 2016. The reconstruction of this lecture hall took place before. New wooden tight windows were installed. 
The aim of the measurements was to record the parameters of the thermal comfort: air temperature, air relative humidity, air velocity, globe temperature, index PMV and index PPD; and the parameters of $\mathrm{CO}_{2}$ concentration.

The measurements were carried out in the small university lecture hall with the sizes 6,6 $\mathrm{x} 14,5 \mathrm{~m}$ in the center of the room in height level $1,10 \mathrm{~m}$. There are five windows built into the external wall with the sizes $2,3 \times 2,3 \mathrm{~m}$. Under each window is recurrent convective heating element. Continuous massive sills are above the heating elements. Four convective heating elements are covered by the decorative slats.

The parameters of the thermal comfort and $\mathrm{CO}_{2}$ concentration were recorded with the device Testo 480. Input data in the measurements were: metabolic rate 1,0 met, clothing insulate 1,0 clo. The measurements of the thermal comfort were carried out in three successive phases that were three tutorial lessons. Each phase took 60 minutes; last 7-10 minutes was break. Different group of students took part in each phase: I - Fig. 2, II - Fig. 3, III - Fig. 4. Students exchanged during the break. The doors and all the small windows were also opened during the break to provide the natural ventilation. Measurement of $\mathrm{CO}_{2}$ concentration was carried out in the following week in one phase, Fig. 5.

Outdoor air temperature was measured and recorded by separate device. Outdoor air temperature increased during the measurement of thermal comfort from the value $10,3{ }^{\circ} \mathrm{C}$ to the value $11,1{ }^{\circ} \mathrm{C}$. Outdoor air temperature increased during the measurement of $\mathrm{CO}_{2}$ concentration from the value $9,1^{\circ} \mathrm{C}$ to the value $10,3{ }^{\circ} \mathrm{C}$.

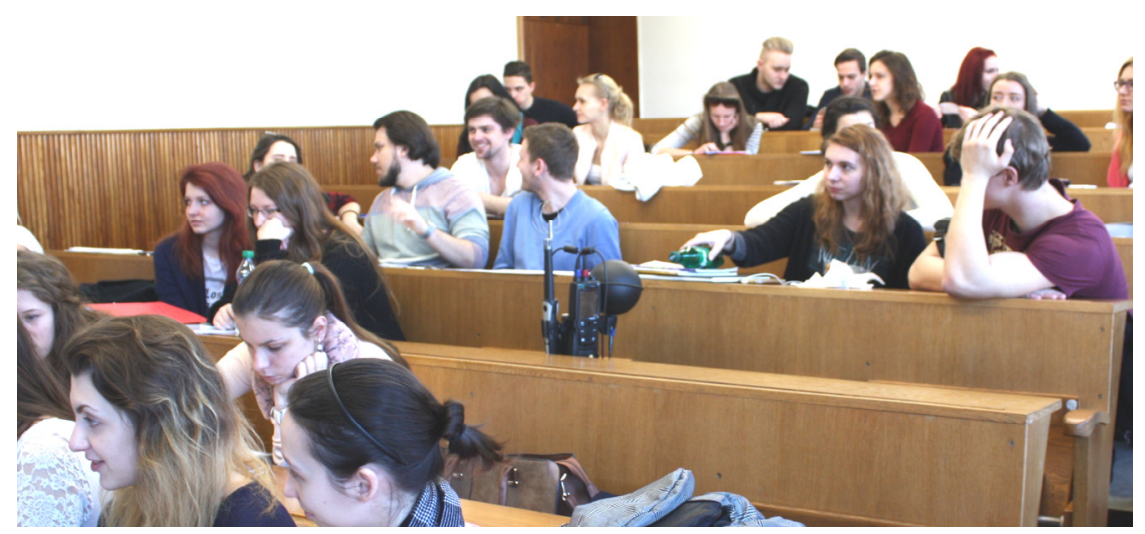

Fig. 2. Measurement in the first phase.

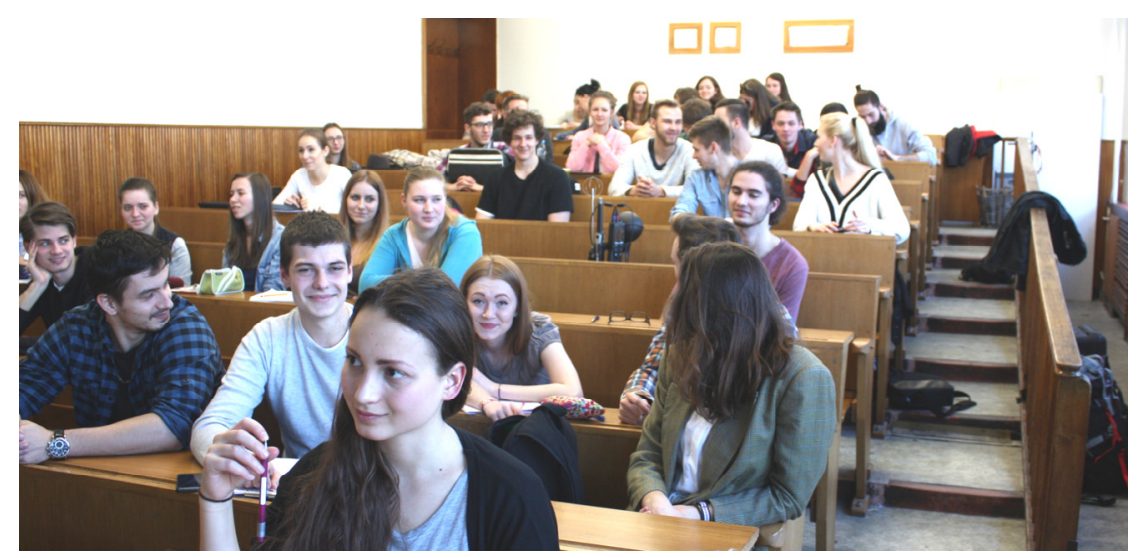

Fig. 3. Measurement in the second phase. 


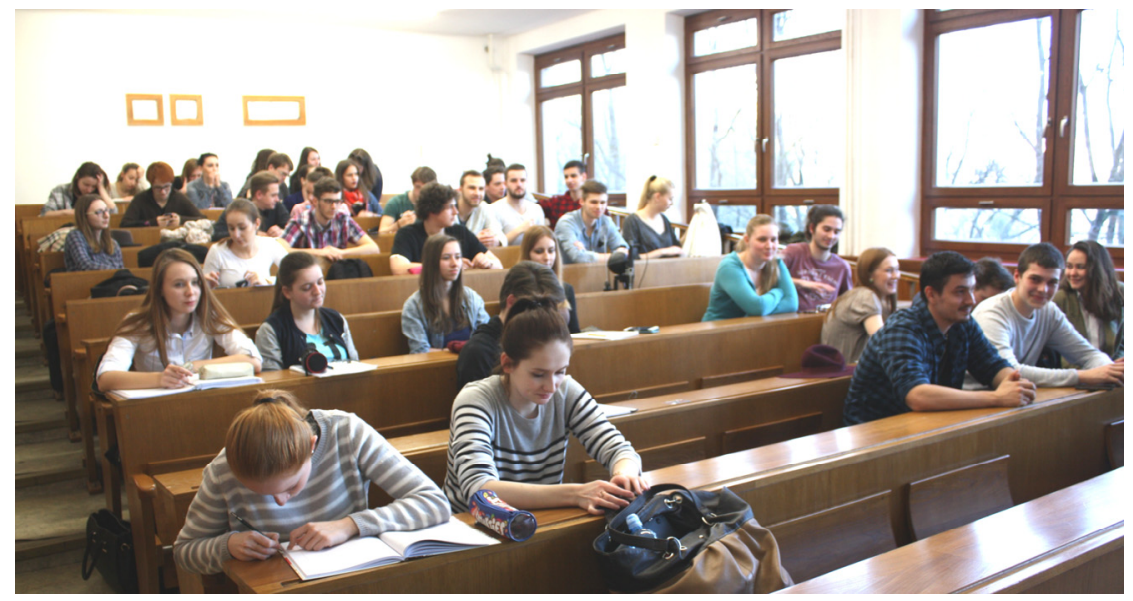

Fig. 4. Measurement in the third phase.

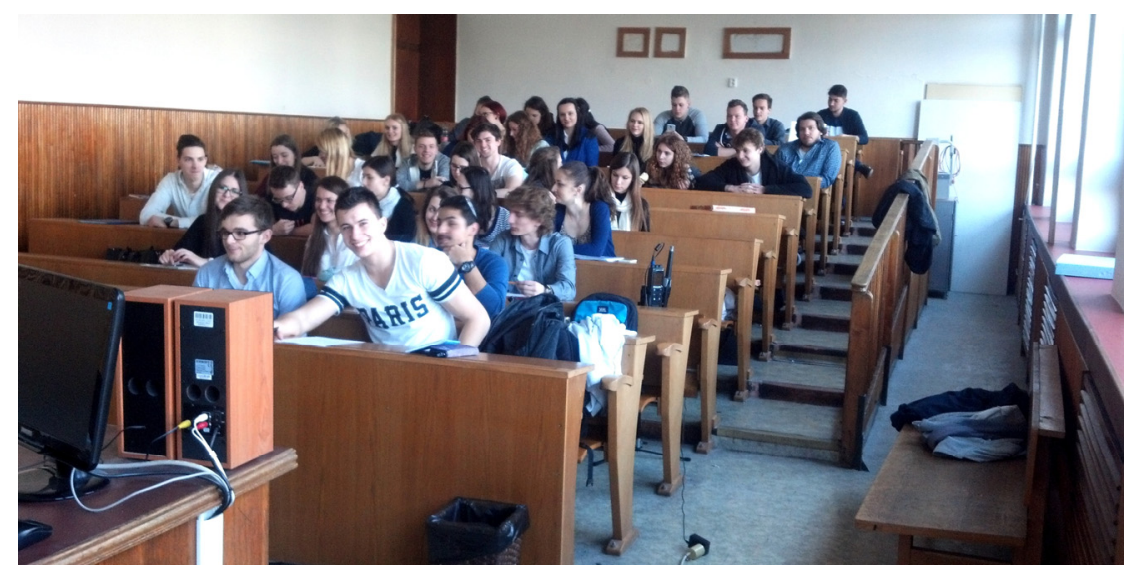

Fig. 5. Measurement of $\mathrm{CO}_{2}$ concentration.

\section{Results and analysis of experimental measurements}

The values of air temperature are showed in Fig. 6 in all three phases in the height level 1,1 in the centre of the room. The values of air relative humidity are showed in Fig. 7, the values of air velocity are showed in Fig. 8, the values of index PMV (Predicted mean vote) are showed in Fig. 9, the values of index PPD (Predicted percentage dissatisfied) are showed in Fig. 10.

Fig. 10 shows the values of $\mathrm{CO}_{2}$ concentration in the first phase during 60 minutes in the height of $1,1 \mathrm{~m}$ above the floor level in the center of the room.

Air temperature (Fig. 6) in the small university lecture hall was high, what relates to more causes. There was no regulation of the heating system after the reconstruction, and after the installation of new windows. Heat losses decreased in the new windows, which was not reflected in the operation of convective heating elements. The low air temperatures in the beginning and in the end of tutorial session show the natural ventilation by windows and door. This natural ventilation during the 7-10 minute break is not sufficient, not only in terms of $\mathrm{CO}_{2}$ load for students, but also in terms of the amount of heat transmitted by students in the interior. This problem shows constantly increasing air temperature in the 
first, then in the second and the biggest values of air temperature were in the third phase of the measurements.

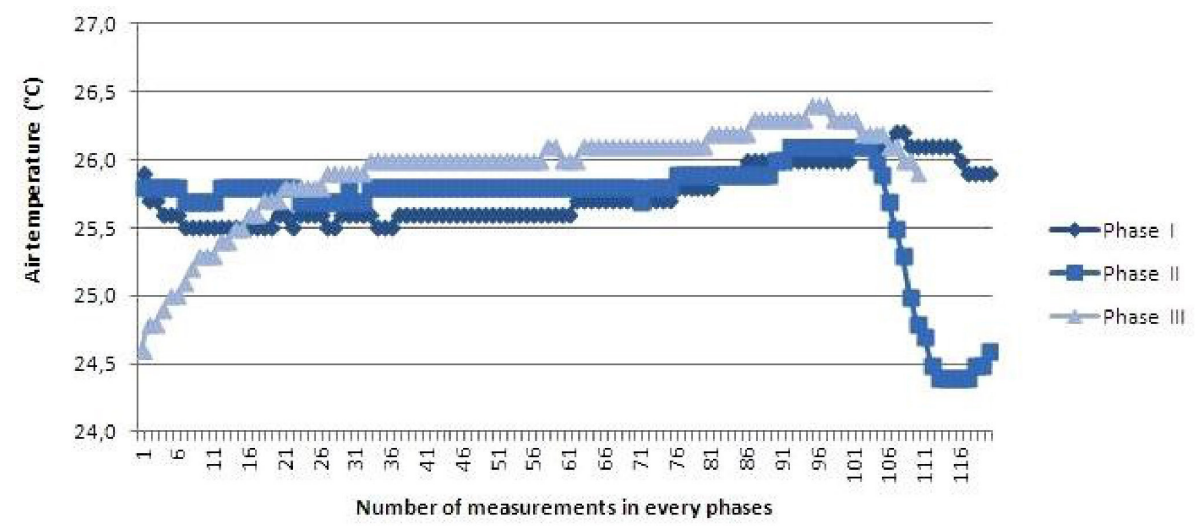

Fig. 6. Values of air temperature in all three phases.

Air relative humidity (Fig. 7) in the small university lecture hall does not have significantly critical values. It is obvious from the graph that air relative humidity values were optimizing itself during the break when there was ventilation. These optimal values kept only couple of minutes after the break. The problems of indoor climate in the lecture hall are pointed out by increasing values of air relative humidity during the first phase, following-up the second and the biggest values of air relative humidity were in the third phase of the measurements.

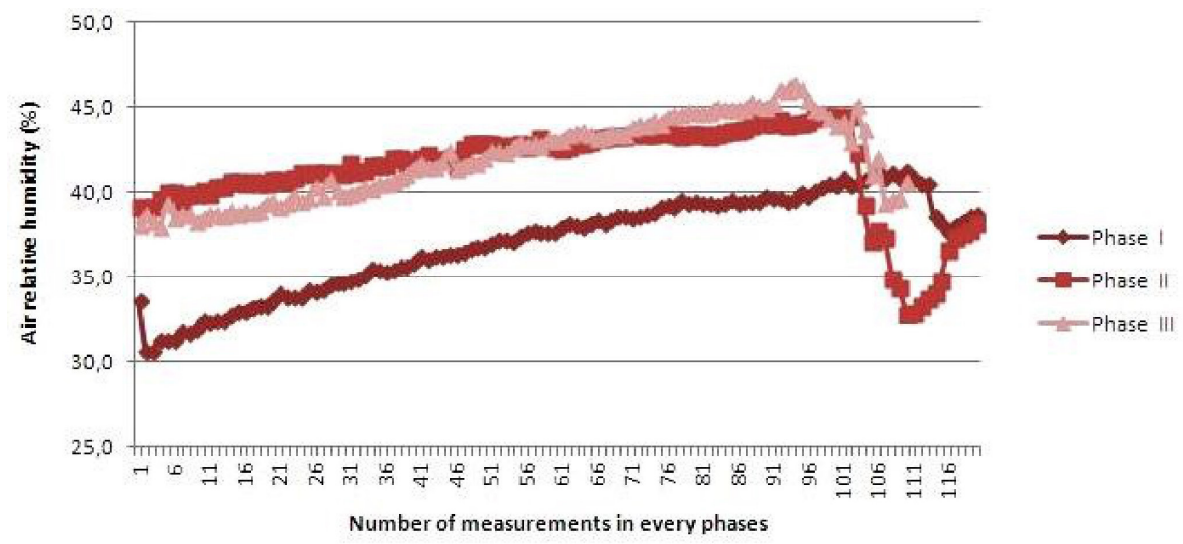

Fig. 7. Values of air relative humidity in all three phases.

Air velocity (Fig. 8) in the small university lecture hall had appropriate values during the tutorial session. High values of air velocity were measured during the break, when there was ventilation and the draught arose between the windows and the door.

Measured values of Index PMV (Fig. 9) and Index PPD (Fig. 10) points out on serious problems with the thermal comfort. Optimal values were not achieved during the tutorial sessions, only short-time during the natural ventilation in breaks. Index PMV and PPD value had still tolerable value during the phase I and II. During the last phase III, Index PMV and PPD value did not have tolerable value in the second half of the tutorial session. Successive increasing values of Index PMV and PPD value during all the phases point out on the problems with the heating system and the missing mechanical ventilation system. 


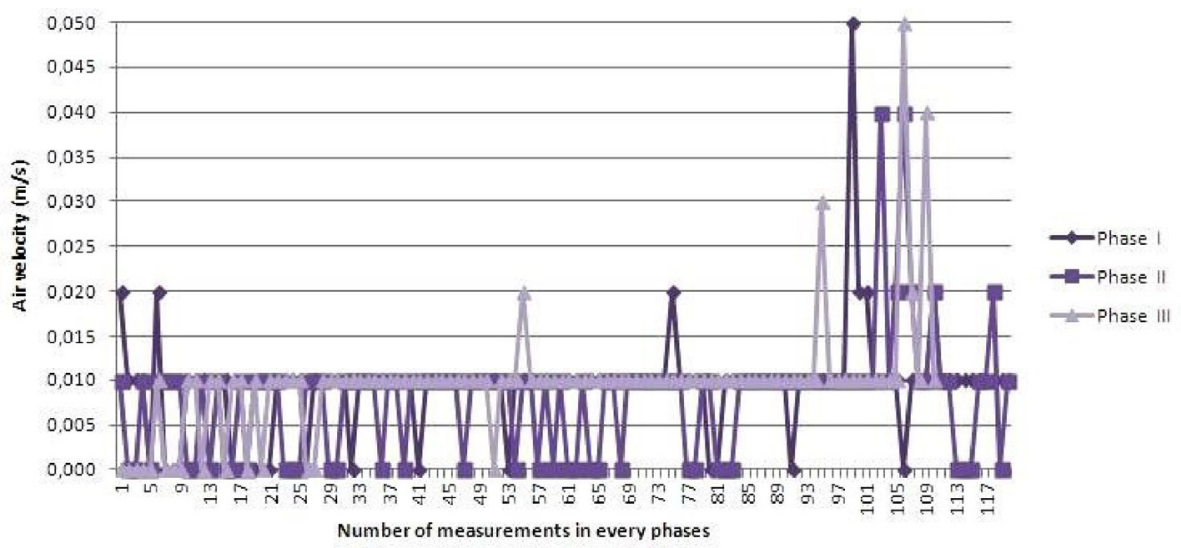

Fig. 8. Values of air velocity in all three phases.

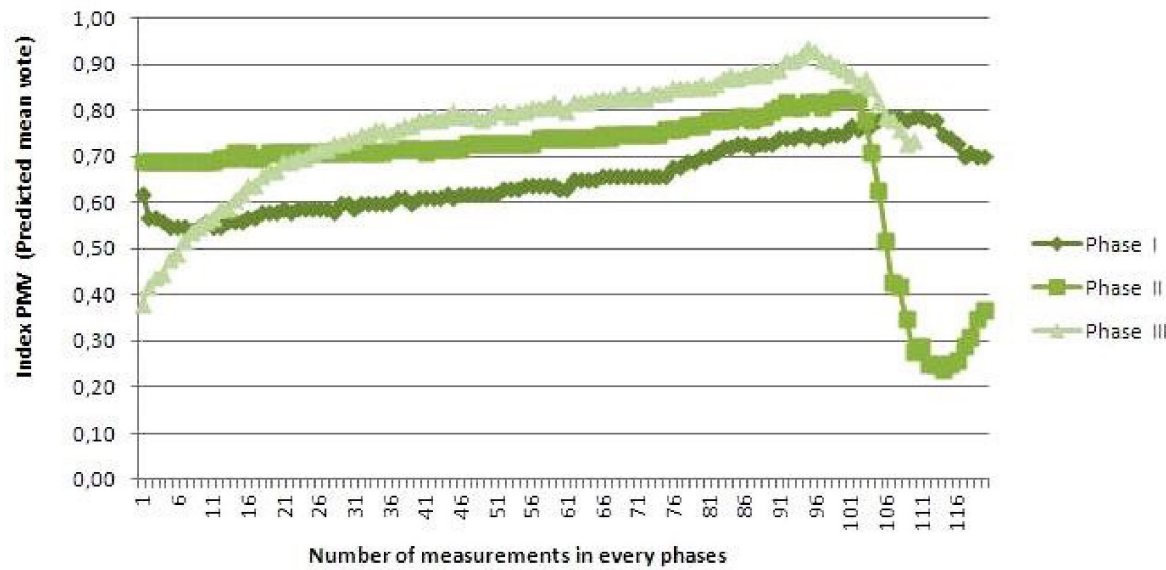

Fig. 9. Values of index PMV in all three phases.

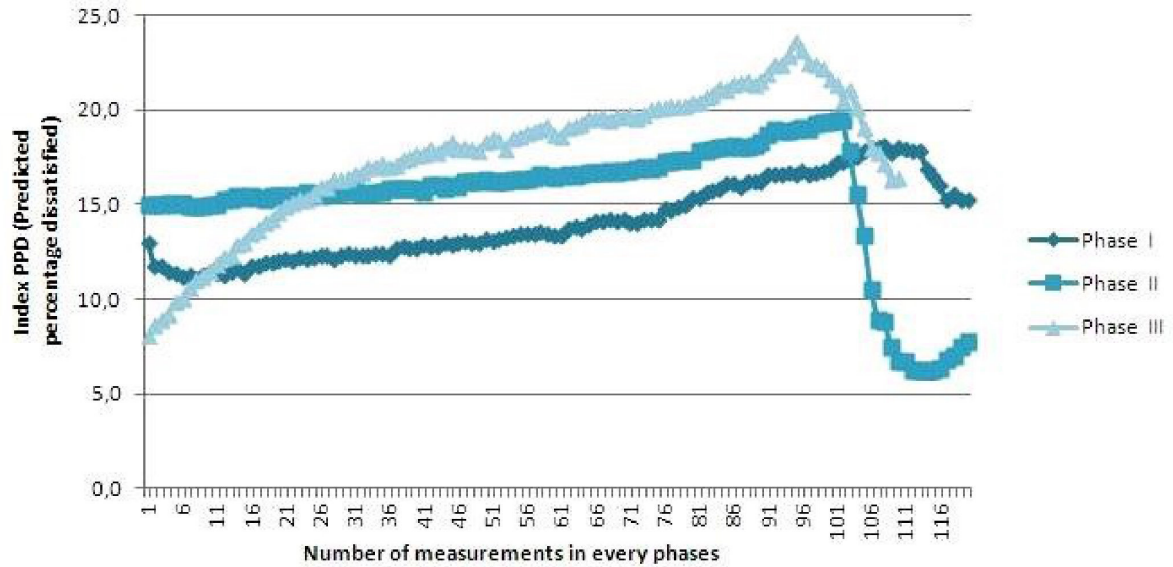

Fig. 10. Values of index PPD in all three phases. 
The values of $\mathrm{CO}_{2}$ concentration (Fig. 11) linearly increased from the value $1327 \mathrm{ppm}$ to the value $2739 \mathrm{ppm}$. These values are inadmissible for the work of students in the small university lecture hall. During the small break between lessons, the doors and all the small windows were also opened. This natural ventilation contributed to the decrease of $\mathrm{CO}_{2}$ concentration on the value $2530 \mathrm{ppm}$, which might be considered as very inefficient. The students complained the most about the quality of the air in the small university lecture hall, had problems with breathing and they had minimal concentration. Results of these measurements showed that during the break, the natural ventilation by doors is completely insufficient. Exchange of the windows brought the quality into the reconstruction, that has not been finished because of the shortage of money and the forced ventilation has not been built. Students' complaints during the lesson were significant, therefore, not only small parts of windows must be opened but also big parts of windows. This caused big paradox; tight energy saving windows are causing enormous heat losses by permanently opened leaves of windows and thus the energy demands have grown. In order to increase the air quality and to achieve energy savings in schoolrooms, it is inevitable to build forced ventilation system.

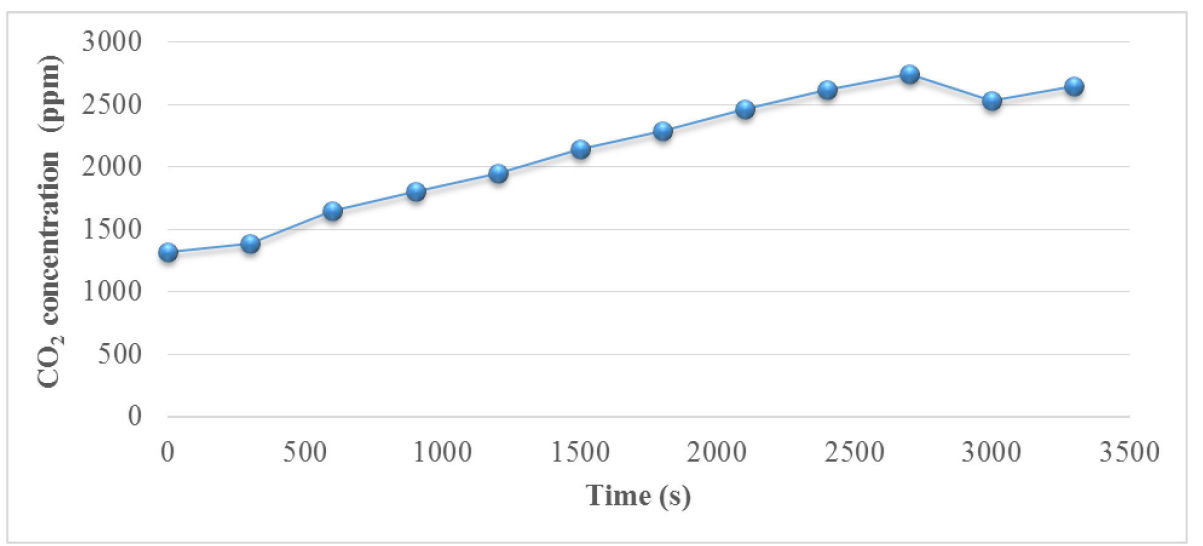

Fig. 11. Values of $\mathrm{CO}_{2}$ concentration.

\section{Conclusions}

Experimental measurements in the small university lecture hall showed the problems with the provision of the thermal comfort. The reconstruction was not thorough. Windows were exchanged for better quality windows, but the massive sill and decorative overlay of convective heating elements were not removed. There was no regulation of the heating system after the reconstruction and the installation of new windows. This fact added to the problems in operation of heating system. There is no controlling element of the heating system, which would adjust the power of convective heating elements to current conditions, number of the students in the small university lecture hall.

Experimental measurements showed that natural ventilation by doors and windows during the break is completely insufficient. Big problems arose with the provision of the air quality because the values of $\mathrm{CO}_{2}$ concentration reached inadmissible values. The students complained the air quality in the small university lecture hall, had big difficulties with breathing and their concentration on the subject decreased sharply. Exchange of windows brought quality into the reconstruction, but represents just the first step; the next step must be the forced ventilation. Students' complaints during the lesson were significant, therefore, the windows must be opened during the entire lesson. It causes big heat losses and 
significant increase of energy consumption. It is inevitable to build forced ventilation system in order to increase the air quality and to achieve energy savings in the schoolrooms. Total reconstruction can bring meaningful results.

During the design of new small university lecture hall, it is necessary to take into the account the requirements for providing the thermal comfort. Therefore, the architectural design, the design of the heating system and the design of the forced ventilation system or the air-conditioning system must be focused on the provision of the optimal indoor climate in a lecture hall.

Scientific paper is published with the support of grant agency KEGA, grant n. 039STU-4/2014.

\section{References}

1. L. Bánhidi, L. Kajtár, Komfortelmélet (Comfort Theory) (Muegyetemi kiadó, Budapest, 2000)

2. STN EN ISO 7730, Ergonomics of the thermal environment - Analytical determination and interpretation of thermal comfort using calculation of the PMV and PPD indices and local thermal comfort criteria (2006)

3. STN EN ISO 7726, Ergonomics of the thermal environment. Instruments for measuring physical quantities (2003)

4. D. Etheridge, Natural Ventilation of Buildings (John Wiley \& Sons, United Kingdom, 2011)

5. M. Jokl, Zdravé obytné a pracovní prostředí (Academia, Praha, 2002)

6. STN EN 15251, Indoor environmental input parameters for design and assessment of energy performance of buildings addressing indoor air quality, thermal environment, lighting and acoustics (2008) 